\title{
Information power and international security
}

\author{
Masahiro Kohara \\ National Institute of Informatics
}

\begin{abstract}
"Information power" has grown and will continue to grow, increasingly important as an element of national power in this age of globalization and the information revolution. This paper aims to describe this increasing role of information power. The information revolution has accelerated the pace of globalization and affects the distribution of power among international actors. Meanwhile, the power of non-state actors has been growing within the international community. This change has had a substantial impact on the power and security of nation-states. In particular, international terrorist groups are posing a serious threat to national security and international peace as the influence of such groups is enhanced by their use of information power. The international community must adopt a new strategy to combat terrorism by promoting international cooperation and its own effective use of information power. Although so-called "hard power" remains a major determinant in the dynamics of international relations, "soft power" of information in today's information age is even more influential and effective. Information power is composed of both information technology and information content. The former is essential to increase military and economic power in the information age. The latter is used to form public opinion and determines public trust, perceived legitimacy, and overall appeal. Every nation must nurture its sources of information power to ensure national security in today's globalized world. Although an in-depth study is required on the relationship between the targets of information power (such as the establishment of legitimacy) and the components of it such power (i.e. a dominant culture or value such as democracy), this paper offers an initial analysis of this relationship.
\end{abstract}

\section{KEYWORDS}

Globalization, information technology, national power, hard power, soft power, information power, international terrorism, national security, democracy, legitimacy

\section{The impact of globalization in the information age}

Globalization is not a unique phenomenon peculiar to the world of today. However, the degree and the speed of global interpenetration are more obvious than ever. The worldwide flow of goods, services, money,

Received November 17, 2004; Revised February 7, 2005; Accepted February $8,2005$.

kohara@nii.ac.jp people, and information have markedly increased and accelerated, driven by liberalization policies and the technological revolution.

Columbus discovered America after two months of sailing. Today, Queen Elizabeth could sail from Europe to America in six days and the (now retired) Concorde could complete the Atlantic flight in three hours and twenty minutes. You are dressed in American jeans or French fashion, eat a hamburger or drink Coca-Cola, watch a Hollywood movie or listen to a 
Sony Walkman made in China. Money flows much more rapidly than ever; this is even more true of information. Globalization integrates the countries and peoples of the world through the enormous reduction in the costs of transportation and communication.

We must make note of two of the major effects of globalization.

First, no nation can avoid confronting various global issues in thus age of globalization. No closed society can prosper in a globalized world. Therefore, more and more states have liberalized their economies and have rendered their regimes more transparent and accountable. Global economic and social transactions are increasingly liberalized, rather than being controlled by the respective states. Therefore, globalization has had a direct, cross-border impact on people's daily lives. A state can no longer protect its people by an artificial wall along its border.

Furthermore, any state, even the U.S. which is the only superpower, cannot afford to resolve on its own various issues caused by globalization. In terms of global issues, international organizations and non-governmental organizations can play increasingly active roles. The former type of organization is regarded as the central to the global governance in terms of a functional approach. The latter type of organization is expected to reflect the interests of the people more directly. Both types of organizations have been working actively to cooperate in areas such as humanitarian assistance. In particular, international NGOs have been conducting a number of noteworthy grass-roots campaigns on various issues relating to landmines, trade, the environment, and more. On the other hand, these organizations have become catalysts for anti-globalization protests on the occasion of almost every major meeting of the International Monetary Fund, the World Bank, and the World Trade Organization.

Second, globalization has a range of both positive and negative effects. One of the negative effects is seen in a widening of the gap between rich and poor. Most people in developing countries still lack access to the world market and the global flow of information. We need to be concerned about these people, citizens, excluded from the globalized world. Otherwise, those who benefit from globalization will face an angry political backlash from those who are marginalized by the increasing inequality among and within some countries. One can in fact point to the phenomenon as a root cause of terrorism. We should be more concerned about this type of negative impact of globalization. It is right that Kofi Annan, United Nations Secretary General, has appealed to the international community to accept the concept of "inclusive globalization," whose purpose lies not only in opening mar- kets but also in expanding opportunity and promoting cooperation.[1]

Another effect of globalization is the spread of goods, money, people, and information throughout the world; this can be both beneficial and harmful to global peace and prosperity. The Asian financial crisis in 1997 and the September 11, 2001, terrorist attacks in the U.S. clearly demonstrated the concept of globalization as a double-edged sword. Such effects could in fact work against freedom and efficiency within the information-network society. Citizens are likely to resign themselves to restrictions on their freedom and privacy drawbacks in exchange for security. This means that globalization could drive nation-states to both toward decentralization and subsequent re-centralization of governance; more specifically, toward the initial diffusion and ensuing concentration of national power among private entities, local governments, and international organizations.

\section{Hard power and soft power as national power}

National power can be classified into two types: "hard" power and "soft" power. Hard power is the ability to make others do what one wants, based on asymmetries in the possession of material resources. Soft power is the ability to persuade others to share one's goals and vision, based on the attractiveness and success of one's ideas.

According to Hans Morgenthau, national power is defined by nine elements: geography, natural resources, industrial capacity, military preparedness, population, national character, national morale, quality of diplomacy, and quality of government[2]. Most of these items are strongly linked to hard power, while only the last four are related to soft power. Other scholars, referred to "realists", also present similar definitions of national power.[3] Soft power represents an increasingly significant force; one which Morgenthau and his followers were not well aware of is soft power. Hard power, such as military and economic power, has previously been the most important factor in international politics. GNP, land area, population, energy production, and military expenditures are measurable and comparable elements of hard power in both actual and potential terms.

National power is dynamic and relative power. First, it is changeable over time. A number of statistics, such as enrollment ratios and adult literacy rates, are important to indices of potential power. Second, in the international community, national power is always compared among nations. In any case, the elements of hard power are no longer the final determinants in the age of globalization and the information revolution.

Soft power can complement hard power. Hard power 
alone is not sufficient to ensure national security and to create sustainable peace throughout the world. Soft power can change antipathy and hatred into favorable feelings and sympathy. International order could be established through the combination of dominant hard power and superior soft power.

Even though it is difficult to measure or assess soft power, unlike hard power, there is a growing perception that soft power has certain capabilities to influence and change others[4].

Individuals and groups wield soft power to influence others. While power has been controlled by the sovereign state since the Westphalia treaty, globalization and the information revolution are likely to diffuse national power, potentially leading to a global threat of anarchy. Non-state actors can enhance their abilities to organize worldwide networks of business, religion, crime, or value-oriented movements and to create new power affecting international politics, security, economy, and more. As an increasing number of non-governmental organizations adopt active global roles, terrorist groups also rapidly are also rising to prominence as international actors.

From the viewpoint of national security, no government can avoid converting stereotypical foreign policies, ones that combine both the application of hard power and soft power.

\section{Information power}

History proves that any war strategy that neglects information power will not bring victory in war. Suntzu, the celebrated Chinese famous philosopher, in fact provided a maxim to the effect, stressing the value of information in war strategy.

Enhanced means of communication and information-dissemination have contributed to the development of the concept of the world as a global village. On the other hand, states and individuals face increasing threats caused by the abuse of advanced information-communication technology. Information power is conducive to global peace and prosperity, but it is also exploited by international terrorists, drug traffickers, and other criminals.

The new war in the 21 st century can thus be described as the "war of information". Information is becoming more important than ever as a basis of power due to the revolution in information technology. Technological innovation has been transforming and enlarging the roles and the staging grounds of nonstate actors. In particular, the mass media has become significantly more powerful in its influence on the decision-making process of nation-states.

Information power is composed of information and communication technology (ICT) and information content. The former enables people to communicate with each other and to collect and disseminate information more widely, rapidly, cheaply, and easily. ICT has been the driving force of the information revolution and has become a determinant enhancing military and economic capabilities. Information content, on the other hand, consists of words and pictures that can be disseminated by ICT: elements used to form a public image and influence public sentiment, with corresponding effects on popular trust, legitimacy, and appeal. Both technology and content are important, but growing attention has come to be paid to the latter. Image is an important factor for state and non-state actors in the information age. For example, the concept of the "brand" is one of the decisive elements of marketing power among private corporations. Similarly, the image of a country in the international community also affects its leadership, agenda, and actions. Hard power alone cannot ensure sustainable support and cooperation. Peace and stability can only be maintained by the trust and legitimacy generated by soft power. In this sense, information power is the most effective type of soft power today in improving national image and in enhancing public trust and legitimacy.

\section{Not diffusion but centralization?}

Half a century ago, in the novel, 1984, George Orwell described a state that controls information in the famous phrase, 'Big Brother is watching'. Contemporary states, however, lose its control over the flow of information in the global web of information networks. Information technology gives individuals and non-state actors the power to communicate and to send messages anywhere. States can no longer monopolize information as before. It is easy to imagine how many central governments have been taken by surprise by the explosion in new forms of online communication. Even if an authoritarian state such as China attempts to control the flow of information over networks, this will turn out to be a costly and inevitably incomplete undertaking. Internet technology is quickly making free expression far harder to control.[5] Furthermore, such attempts at control may reduce the dynamism of economic development

Therefore, both decentralization and the trend toward 'smaller governments' are inevitable phenomena in the age of globalization. This trend has also been driven by the liberalization that characterized 1990's after the collapse of communist regime in the former Soviet Union and the eastern European countries.

On the other hand, the security concerns[6] resulting from international terrorism in the 21 st century are 
reversing the earlier trend toward the decentralization or diffusion of power. September 11 changed the recognition of the real threats to the security of the U.S. among many Americans, a population that had never imagined a devastating attack on their homeland since the end of the Cold War. Few thought that a terrorist could board a plane with a bomb. Security suddenly became the top priority of the US government. The political battle ground in the presidential election in 2004 was defined by the war on terror.

Counterterrorism efforts have been seen everywhere? from airports to office buildings to cargo ships to hospitals[7]. High-tech devices have been developed to protect people from terrorist attack. The U.S. government requires that all cell phones be equipped with GPS features to pinpoint the owner's location by the end of 2005, and other countries may follow suit[8]. Several U.S. states are using face-recognition systems to check for individuals who have obtained multiple drivers' licenses by lying about their identities[9]. Most foreign travelers to the US are required to provide digital fingerprints and photographs to US authorities as part of an expanded border security scheme[10]. More surveillance cameras have been installed in Washington, D.C..[11] All of these measures are direct result of the aftermath of the September 11 th attacks.

In this sense, a democratic nation-state is transformed into a high-security state under close surveillance. If Orwell could observe today's world, he would be surprised to note that despite his prescient warnings, "Big Brother is indeed watching."

The 'fortress state,' one that tightens control over borders and places first priority on security, however, goes against the age of globalization and democratization. Such an approach could easily lead to a tougher, more regulated society, and is likely to turn out to be a costly and stifling in the long run. Yet if the choice is between security and privacy, however, most people will probably choose security[12].

\section{National security and terrorism}

September 11 symbolized a new dimension of terrorism: the emergence of non-state actor wielding violence on a large scale. If you wanted to kill 5,000 people at once even a few decades ago, you would need to have control of a state. Today, a small number of terrorists can do the same by hijacking a civil airplane or acquiring a small-sized nuclear bomb on the black market. David Halberstam, in "War in a Time of Peace," describes an American society, open to the world, vulnerable to attack by a terrorist infiltrating the U.S. on foot with a nuclear weapon in his suitcase.

The emergence of a world government does not seem imminent. Therefore, the role of the nation-state with a monopoly on systematic violence has been justified in terms of national security. The world, however, could in fact become more dangerous than in the Cold-War era, as globalization and the information revolution have enabled non-state actors to gain sufficient power enough to undermine national security. It is now easier, in an increasingly globalized world, for terrorists to exploit sophisticated technology, communications, and resources for their criminal objectives. A small number of terrorists can even become capable of waging a war against a state. In particular, suicide attackers transform powerlessness into extraordinary power. No credible threat can be made against those who have no desire to survive.

The traditional concept of war, which the international community has exerted efforts to prevent and regulate, consists of a war between one state and another. The war on terrorism, however, is not a war between two states but instead is an asymmetric struggle between a state and a group of people not bound by rules and regulations.

Furthermore, a terrorist group is not a visible army and will not wait to be detected. It is difficult to specify where the battlefield will be. We should also note that terrorism is not state-sponsored but society-sponsored. Together these characteristics being to define the ways in which the war on terrorism is a new type of war.

How can we deter someone who could be anywhere and who is willing to die? This response to this question lies in reducing the relative role of military power in the age of information.

Various explanations have been put forth as to the root causes and motivations of suicide attackers, focusing on poverty, lack of opportunity, or ethnic and religious strife. Political motivation, however, should not be neglected. In the case of Palestinian suicide attackers, the leadership of radical groups such as Hamas has manipulated religion effectively in its attempt to attain a secular goal: to coerce the Israeli government to change its policies and to leave the Palestinian territories. In fact, there is currently no agreed-upon definition of the word "terrorism," mainly because some argue that this is a subjective concept and that it has a particular political motivation when it is used simply to describe[13]: "violence that I do not support"[14].

The general principle adopted by most of the governments coerced by "terrorists" in any form ( such as the one of Palestine or Chechen suicide bombers), however, involves a refusal to negotiate. The slogan of "never yield to terrorism" is likely to be as firm as the speaker is adamant. This approach underscores the dif- 
ficulty in solving the issues broadly referred to as "terrorism".

These features of terrorism have fundamentally changed views of national security. The Bush administration has adopted a doctrine of pre-emptive action against 'any rogue state' that harbors and sponsors a terrorist group. For Bush, the September 11 attacks were the catalyst for a war not just against Osama bin Laden and his al-Qaeda network but also against any state that harbored, sponsored, or supported terrorists.[15] Bush's advisers have argued that terrorist organizations cannot function effectively without the support of rogue states such as Iraq. However, a network of like-minded groups of terrorists seems to be beyond the control or influence of any single state. If this is the case, state military power — which is designated to protect its territory and people from any military attack by another state - is not sufficient to deter a terrorist attack. Nuclear deterrence,

For example, cannot thwart a terrorist attack. The presence of sizable troops in Iraq alone can neither contain a ruthless insurgency employing tactics such as suicide bombings nor support 'nation- building' within a failed state.

\section{New strategy on terrorism}

The relationship between national military power and a national sense of security is not necessarily directly proportional in the 21 st century. The year 2001 was a symbolic turning point during which the world witnessed an apparent 'democratization of mass violence.' In this context it is worth reconsidering how best to address the threat of terrorism in terms of power. Following are suggestions as to a strategy we are proposing to solicit an assessment of its strengths and drawbacks.

First, the strategy should combine both hard power and soft power. A war on terror using military power alone cannot defeat terrorism. Any state that continually resorts to military power must change course. U.S. strength cannot be sustained only through military and economic superiority; it must also project American values. Roosevelt and Truman believed in this approach. The U.S. should not neglect soft power but instead should seek an ideal combination of hard power and soft power.

Second, the unilateralism of the U.S., in disregard of international cooperation, should be modified if we are to transform 'imperial' unilateralism into rule-based leadership. Such a move will be necessary if we are to create a new international order conducive to global peace and prosperity.

The issue of the war on terror will depend on how the U.S. behaves in order to create a new international order able to guarantee global peace and prosperity ? whether it act with the hegemony of a superpower or through cooperation and respect for diversity. If the U.S. campaign against terrorism is seen to be unilateral, it will probably fail. If it exerts every effort to form broad coalitions to suppress terrorism, it will likely face fairly encouraging prospects.

The new strategy should adopt a comprehensive approach to power combining both military and nonmilitary strengths in addition to greater multilateral cooperation within the international community.

Both military power and non-military power are required to defeat terrorism, including a global lawenforcement and intelligence-sharing apparatus capable of shutting down international criminal networks are necessary to defeat terrorism.

In the long run, the root-causes of terrorism must be addressed through the international cooperation. In this context, the international community should define a common policy on terrorism, and it should also address the difficult situations faced by the weak and failed states in which governments have become ineffective, illegitimate, tyrannical, and corrupt, if it is to curb the infiltration of terrorism into such states. International assistance to these countries should entail institution-building, justice, rule of law, good governance, and economic and social development.[16]

International cooperation is also required to address not only terrorism but also the threats of infectious diseases, nuclear proliferation, global warming, and an array of additional global issues. For example, a global disarmament initiative involving the collection and elimination of weapons in exchange for health or employment programs for ex-combatants is a useful approach to establishing peace and in preventing the recurrence of conflicts.[17] International cooperation initiated by the United Nations is also essential. The disarmament, demobilization, and reintegration of ex-combatants (a process referred to by the acronym "DDR") at the post-conflict stage is important in nation- building in failed states that are too weak to suppress terrorists. In order to crack down on international terrorism, to create a global antiterrorist coalition is certainly a prerequisite.

If the U.S., the world's leading democratic country, would listen more to others, and if, as the world supreme military power, it were to value and nurture soft power, its leadership would be respected and accepted by the entire international community.

\section{Information war and legitimacy}

Terrorist groups can enhance their influence and force by means of information technology. The shocking pictures of the beheading of a hostage may increase a terror among the world audience. At the same time, the terrorists issue messages saying that 
their fight is justified as an Islamic Jihad against 'American imperialism'. On the other hand, Saddam Hussein's capture and the announcement of the schedule of general elections in Iraq were reported by the American media with some restoration of confidence in establishing security and democracy in Iraq. Which message will gain the support of a majority of the Iraqis? How can we separate the majority as well as the potential suicide attackers from a mastermind or a central figure of a terrorist group?

Time, the popular American weekly magazine, pointed out that the U.S. image in the Muslim world is unlikely to improve as long as U.S. forces are embroiled in combat in Iraq and Palestine aspirations for statehood are unfulfilled.[18] Image has increasing importance in world politics and an American foreign policy characterized by unilateralism creates a poor image, reflecting a high-handed posture adopted to force] other countries to listen.

The U.S. should strengthen its investment in 'public diplomacy' programs aimed at improving the image of the U.S. in Muslim countries. There are many arguments for soft power that favors cooperation over coercion.[19] Soft power in the information age is composed of the dominant culture and its ideas, access to multiple channels of communication, and credibility enhanced by domestic and international performance.[20] Such power arises from the attractiveness of a country's culture, political ideals, and policies. Any country that can set the agenda in world politics in such a way as to be viewed as legitimate by other countries and people will enhance its soft power.

A new global order should be based on justice, as there can be no sustainable peace without justice. The problem lies in judging and deciding what actions correspond to "justice". Although global governance formed by international law and by the United Nations carries the authority to legitimize national conduct, the effectiveness of global governance is often called into question. If a nation's power is overwhelming, it can do and justify anything it wishes based on realpolitik: power is justice. Nonetheless, the assessment of justice in the world is becoming democratized as more and more people have begun to gain access to the global flow of information and to communicate their own judgments on world affairs. Therefore, legitimacy is now more important than ever in international politics. Without legitimization based on international norms and procedures, national power may come to be perceived as a resource or a tool that automatically invites suspicion and challenge. In general, national power should be used and can only be sustained in its national function based on popular support and solid justification in domestic society and in the inter- national community. Therefore, every government must persuade and appeal to those both inside and outside of the country through the mass media and communication networks such as the Internet.

The role of information power will thus become essential in ensuring legitimacy of state action in the 21 st century.

\section{Conclusion}

Some argue that in the long term, the spread of democratic governance is the best guarantor of peace and security in the world.

It is very true that democracy promotes peace and prosperity. Modern history has provided numerous supporting examples.

First, some can argue that democratic countries tend to avoid war one another. This argument is persuasive in light of a study of history. Second, democracy promotes transparency in politics, the rule of law, and equal opportunities in terms of economic development.

On the other hand, we should recognize that a democracy is a delicate political system that is sustained by a contract with the people. Legitimacy is a precondition for a lasting democracy. Most important in this context is absorbing the opinions and interests of minorities in democracy. If this fails, a democracy is doomed. The result of the American presidential election showed the emerging division of public opinion in the U.S.. Moreover, perceptions of American unilateralism remain notably widespread in Europe and in Muslim nations, while the war in Iraq has undermined American credibility abroad. According to a public survey in Europe and Muslim countries, the loss of trust in the U.S. varies little across countries: in other words, America is simply distrusted.[21] The situation is thus not ideal, and runs generally counter to the advancement of global peace and prosperity. The president faces the challenge of listening to as many different ideas and opinions as possible if he is to gain the trust of those who did not or who could not vote for him and thus to maintain the stable functioning of democratic system[22].

Furthermore, democracy is an ideal political system not only within one nation-state but also in terms of today's globalized world. International public organizations taking on greater responsibility and playing larger roles in tackling global issues must reflect the different voices of developing countries. Both democratization and transparency in global governance are necessary in realizing a more equal and stable world.

However, without security, democracy and freedom are impossible to realize and maintain. To promote global peace and prosperity based on the values of 
freedom and democracy, the negative aspects of globalization - such as worldwide terrorist groups connected by global networks and ideologies - must be addressed through global cooperation; for example, through a global antiterrorism coalition in which both states and non-state actors (including supranational corporations, NGOs, and individuals) are asked to participate.

Democracy is a universal value that all people can enjoy in terms of the freedom to elect one's own leaders, and should be shared by all, regardless of creed, history, race, or culture.

Nonetheless, democracy can have different models in different countries subject to different conditions and backgrounds. However, it takes quite a long time to establish and consolidate any model of democracy in a society that has no democratic experience. More importantly, we must be well aware of the importance of autonomy and self-help among those wishing to determine and create their own future

Therefore, imposing a value such as democracy on a population in a different country is not justified by its universality. It is ideal and sustainable for the indigenous people to choose democracy. E. H. Carr pointed out that the military power of Napoleon was notoriously the most potent factor in the propagation throughout Europe of the ideas of 1789[23]. However, the major cause of the eventual failure of Napoleon's armies in the wake of nationalism in occupied countries was his use of hard power justified by spreading universal freedom, equality, and brotherhood.

Therefore, the combination between hard power such as military power and soft power such as democracy cannot guarantee the successful establishment of the stable order.

In this regard, the significance of the information power must be recognized on the basis of respect for diversity of culture and values in the world. The collapse of Berlin Wall is one precious lesson of history.

Information power will become more and more important for state actions in the international community to get the popular supports by legitimizing those actions.

\section{References}

[1] Kofi A. Annan, "Making Globalization Work for the Poor," The Independent, Dec. 12, 2000.

[2] Hans J. Morgenthau, Politics Among Nations, New York: Alfred A. Knopf, 1978, pp. 117-155.

[3] Frederick Hartman in "The Relations of Nations" suggests six elements: demography, geography, economy, historical-psychology, and organizational-administration. Werner J. Feld in "International relations:
Transnational Approach" finds seven elements: geography, population, economic development, science and technology, traditions and social psychology, government and administration, and military organization.

[4] J. A. Hart classifies three different ways of empirically observing power. They are power as a resource, power as a relationship, and power as a structure. He points out that potential power measured in terms of control over a resource can be converted in some manner into actual power which is control over others or over outcomes. ('ISDN and Power' p. 8, Discussion Paper 7, Center for Global Business, the Business School of Indiana University)

[5] International Herald Tribune reports China's recent censorship. (June 28, 2004)

[6] James N. Rosenau pointed out "the primary threat of the internet is the way that it facilitates new nontraditional forms of warfare and violence, particularly from non-state actors and terrorists" in his book, Information Technologies and Global politics, State University of New York Press, 2002.

[7] President George W. Bush, State of the Union, Jan. 28, 2003. He mentioned terrorism in his remarks: "All told, more than 3,000 suspected terrorists have been arrested in many countries." "We've intensified security at the borders and ports of entry, posted more than 50,000 newly-trained federal screeners in airports," "Our government must have the very best information possible, and we will use it to make sure the right people are in the right place to protect all our citizens."

[8] Newsweek, June 14, 2004, p. 69.

[9] International Herald Tribune, May 31, 2004.

[10] Financial Times, March 14, 2004.

[11] Asahi Weekly Magazine AERA (in Japanese), Aug. 4, 2003, p. 34.

[12] A survey indicates that a sizable number of Americans believe that we shall give up personal freedoms to ensure security. For example, $49 \%$ of people surveyed said the First Amendment which guarantees freedom of speech, religion, the press, assembly, and petition goes too far in the rights, compared to $22 \%$ in $2000,39 \%$ in 2001. The survey was conducted since 1997 by the Center for Survey Research \& Analysis at the University of Connecticut. http://www.freedomforum.org, Aug. 29, 2002.

[13] For instance, The Syrian Arab Republic renewed its call for holding of an international conference within the United Nations framework to establish a definition of terrorism and to distinguish it from the right of people to engage in legitimate struggle against foreign occupation. ("United Nations General Assembly $\mathrm{A} / 59 / 210 ”)$

[14] International Herald Tribune, Editorials and Commentary, Feb. 18, 2004.

[15] Time, Nov. 1, 2004, p. 30.

[16] These points have been pointed out by many experts 
and international prominent figures such as secretarygeneral of United Nations, Kofi Anan, or the president of African Union, Joaquim Chissano. See, for instance, International Herald Tribune, May 8-9, 2004.

[17] Weapon-swap for cash is not always effective to address the root-cause of conflicts. Financial Times reported that arms dealers took advantage of the Iraqi interim government's groundbreaking disarmament scheme. (October 19, 2004)

[18] Time, Nov. 1, 2004, p. 33.

[19] Joseph S. Nye, The Paradox of American Power, New York, Oxford University Press, 2002, p. 9.

[20] Joseph S. Nye, The Paradox of American Power, New York, Oxford University Press, 2002, p. 69. Nye invented the term "soft power."

[21] The Pew Research Center conducted a survey on March 16, 2004 and announced its summary. There are some noticeable findings. For instance, rating of the U.S. favorability dropped drastically from 2002 to 2004: France (37\% from 63\%), Germany (38\% from $61 \%$ ), Britain (58\% from $75 \%$ ), and rating of suicide bombings justifiable is high in Muslim countries: Jordan (70\%), Morocco (66\%), Pakistan (46\%).

[22] $48 \%$ of voters voted for the challenger, John Kerry compared with voting rate for Bush, $52 \%$.

[23] Edward. H. Carr, The twenty Years' Crisis 1919-1939, London, Macmillan, 1946, p. 125.

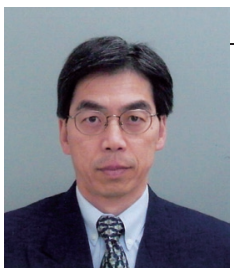

\section{Masahiro KOHARA}

Masahiro Kohara received the B.A. degree from Tokyo University in 1980, and also received M.A. degree in Asian Studies from U.C.Berkley. Since 2003 he has been a professor of National Institute of Informatics after having worked for Ministry of Foreign Affairs in Japan. His research interests are international relations and Asian affairs. 